Colloids and Surfaces

A: Physicochemical and Engineering Aspects 180 (2001) 1-6

\title{
Adsorption of aqueous nitrophenols on clinoptilolite
}

\author{
T. Sismanoglu*, S. Pura \\ Department of Chemistry, Engineering Faculty, University Of Istanbul, Istanbul, Turkey
}

Received 19 April 1999; received in revised form 21 August 2000; accepted 22 August 2000

\begin{abstract}
The adsorption of $o-, m$ - and $p$-nitrophenols on clinoptilolite type natural zeolite has been studied as a function of the solution concentration and temperature. The adsorption rates were observed to be equal to the first-order kinetics. The rate constants were calculated for $25.0-40.0-50.0^{\circ} \mathrm{C}$ at constant concentration. The activation energies, $\left(E_{\mathrm{a}}\right)$ for nitrophenoles adsorption on zeolite, were estimated using the Arrhenius equation. Thermodynamic parameters were calculated for all nitrophenols. Adsorption isotherms of $o-, m$ - and $p$-nitrophenols on natural zeolite were determined. These isotherms were modeled according to the Freundlich and Langmuir adsorption isotherms. The isotherms for nitrophenols on clinoptilolite were assigned as $\mathrm{L}$ curves. The $\mathrm{L}$ curve of $p$-nitrophenol is two step while the L curves of $o$ - and $m$-nitrophenols are one-step. (C) 2001 Elsevier Science B.V. All rights reserved.
\end{abstract}

Keywords: Adsorption rate; Natural zeolite; Nitrophenols; Freundlich and Langmuir type isotherm

\section{Introduction}

The adsorption characteristics of several phenolic pollutants on various adsorbents have previously been extensively investigated [1]. However, most of the work was on the adsorption behaviour of activated carbon and carbon black samples [2]. The cost of these adsorbent minerals indicate that cheaper and easily obtainable unconventional adsorbents such as should also be studied for the removal of pollutants from water. Suitable candidates would be the natural zeolites, with more than 40 types, forming the greatest mineral family. Among them, clinoptilolite is the most abundant one, and generally occurs as a

\footnotetext{
* Corresponding author.
}

diagenetic alteration product of volcanic glassy material and matrix in volcano sedimentary rocks. In the present work, the adsorption of organic pollutants, are ortho-, meta- and paranitrophenols $(o-, m$ - and $p$-Nph), on the clinoptilolite grade of natural zeolite was investigated and their various adsorption parameters were determined.

\section{Materials and methods}

Adsorption characteristics of $o-, m-$ and $p$-Nph on clinoptilolite were studied using the batch method. The clinoptilolite was obtained from the rhyolitic tuff level of the Neogene volcano sedimentary sequence in Gördes, West Anatolia, Turkey. Zeolite-rich tuff contains usually mainly 
authigenic minerals (clinoptilolite, smectite, illite, quartz, opal-CT, K-feldspar and calcite) and a small amount of phenocrysts (quartz, albite, ortoclase and biotite) [3]. Representative tuff samples used in this study have a clinoptilolite content of $90 \%$, as estimated by the quantitative X-ray model analysis method [4]. The chemical composition was reported to be $69.30 \%-\mathrm{SiO}_{2}, 11.90 \%-$ $\mathrm{Al}_{2} \mathrm{O}_{3}, 0.11 \%-\mathrm{TiO}_{2}, 0.65 \%-\mathrm{Fe}_{2} \mathrm{O}_{3}, 2.39 \%-\mathrm{CaO}$, $0.80 \%-\mathrm{MgO}, 0.29 \%-\mathrm{Na}_{2} \mathrm{O}, 3.09 \%-\mathrm{K}_{2} \mathrm{O}, 0.04 \%-$ $\mathrm{SO}_{3}, 7.89 \%-\mathrm{H}_{2} \mathrm{O}^{+}$and $3.48 \%-\mathrm{H}_{2} \mathrm{O}^{-}$. The unit cell average $\mathrm{Na}^{+} \mathrm{K} / \mathrm{Mg}^{+} \mathrm{Ca}$ and $\mathrm{Si} / \mathrm{Al}$ ratios of clinoptilolite crystals were analysed by scanning electron microscope (Jem-T330 model) and energy dispersive X-ray spectro-meter (Tracor-Northen 5400 model) and were found to be 1.37 and 5.11, respectively.

The mineral was sieved to obtain a particle size smaller than $125 \mu \mathrm{m}$ and washed several times with distilled water until no suspended material was observed in the leachate. The samples were then dried in an oven at $110^{\circ} \mathrm{C}$ and stored in a calcium chloride dessicator until use. The pure crystalline $o-, m$ - and $p$-Nph used in the adsorption studies were obtained from Merck. Double-

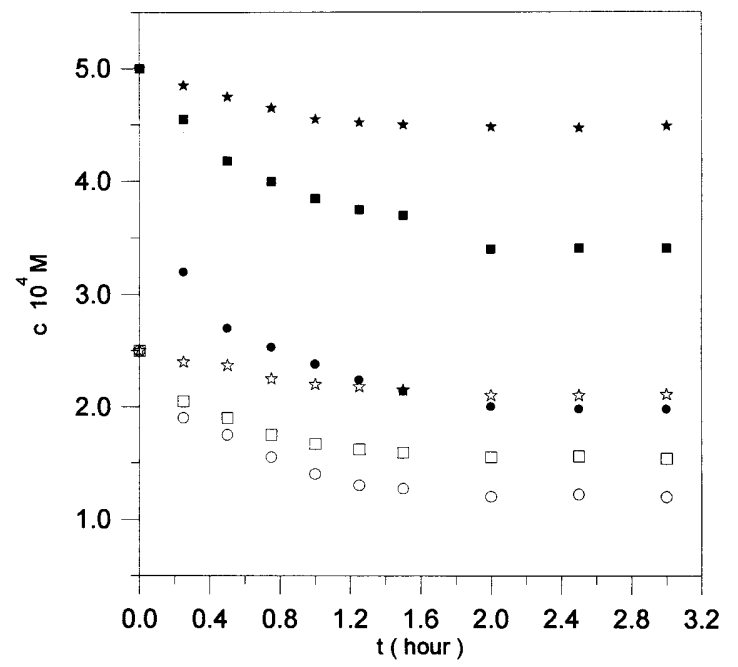

Fig. 1. Plot of concentration of nitrophenol $(c)$ in bulk against time due to adsorption at the (clinoptilolite) zeolite-water interface at temperature $25^{\circ} \mathrm{C} ; p$-nitrophenol $\left(c_{0} ;\right.$ o. $2.5 \times 10^{-4}$ $\left.\mathrm{M} ; ~ ○ .5 .0 \times 10^{-4} \mathrm{M}\right), o$-nitrophenol $\left(c_{0} ; 2.5 \times 10^{-4} \mathrm{M}\right.$; $\left.5.0 \times 10^{-4} \mathrm{M}\right)$, and $m$-nitrophenol $\left(c_{0} ;\right.$ 放 $2.5 \times 10^{-4} \mathrm{M} ; \star$. $\left.5.0 \times 10^{-4} \mathrm{M}\right)$. distilled water was used throughout the experimental work. Solutions of $o-, m$ - and $p$ $\mathrm{Nph}$ at initial concentrations of $1.0 \times 10^{-4}$, $1.67 \times 10^{-4}, 2.5 \times 10^{-4}, 4.0 \times 10^{-4}$ and $5.0 \times$ $10^{-4} \mathrm{Mol} / 1$ were used. Ten millilitre of $o-, m-$ and $p$-Nph solutions, of known initial concentrations were added to $0.2 \mathrm{~g}$ zeolite samples in colored flasks. The mixtures were shaken in a thermostatic shaker waterbath at constant temperature. Preliminary experiments showed that the most reliable determinations and thus the best adsorption behaviour was obtained with the initial concentration of $5 \times 10^{-4} \mathrm{Mol} / 1$ at $25.0,40.0$ and $50.0^{\circ} \mathrm{C}$. At different timeintervals, flasks were removed from the shaker and the liquid and solid phases were separated by centrifuging at $3000 \mathrm{rpm}$ for 20 min. The concentration of $o-, m-$ and $p$ - Nph in the solution after adsorption at different times was determined spectrophotometrically. All the spectrophotometer measurements of aqueous $o-$, $m$ - and $p$-Nph were made with a Perkin-Elmer $554 \mathrm{UV}$ spectrophotometer. The absorbance values of $o-, m$ - and $p$-Nph were measured at 350, $330,320 \mathrm{~nm}$, respectively. These were used to calculate the absorbate concentration in solutions during kinetic studies. The effect of temperature, at constant concentration on the rates of adsorption of $o-, m$ - and $p$-Nph was determined.

\section{Results and discussion}

\subsection{Adsorption kinetics}

The flasks were shaken for $3 \mathrm{~h}$ to attain the equlibrium. $O-, m$ - and $p-\mathrm{Nph}$ adsorption was accepted to be complete at the end of this period. The variation of nitrophenol concentration, $c$, with time, $t$, during the non-equilibrium adsorption of different $o-, m$ - and $p-\mathrm{Nph}$ by zeolite is shown in Fig. 1. The change in the amount of solute adsorbed per unit weight of adsorbent with time was found to fit the first-order kinetics equation,

$\ln \left(X_{e}-X\right)=-k t+I$

where, $X_{\mathrm{e}}$ : amount of adsorption material at equlibrium; $X$ : amount of adsorption material in 


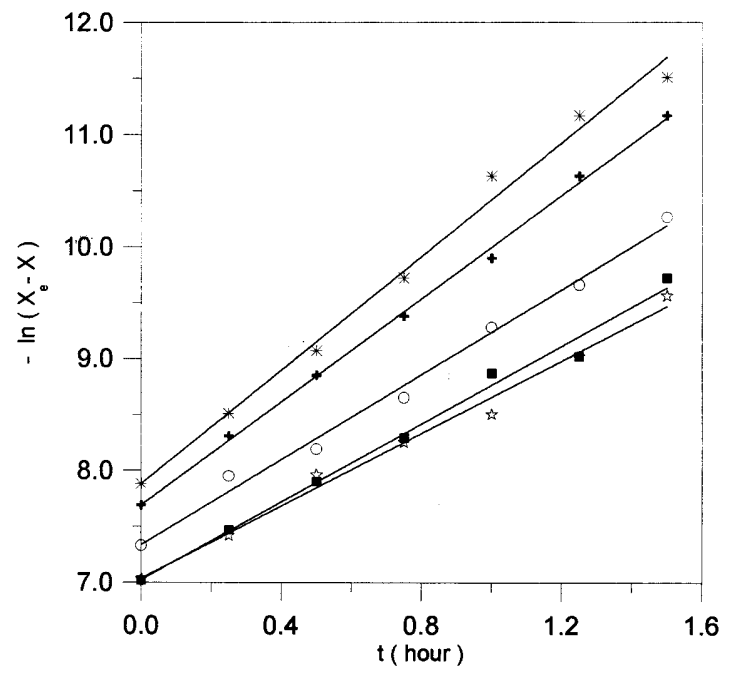

Fig. 2. Plot of $\ln \left(X_{\mathrm{e}}-X\right)$ vs $t$ of $p$-nitrophenol at $25^{\circ} \mathrm{C} ;(*)$ $1.0 \times 10^{-4} \mathrm{M},(+) 1.67 \times 10^{-4} \mathrm{M},\left(\right.$ o) $2.5 \times 10^{-4} \mathrm{M}$ $4.0 \times 10^{-4} \mathrm{M}$, (㧒) $5.0 \times 10^{-4} \mathrm{M}$.

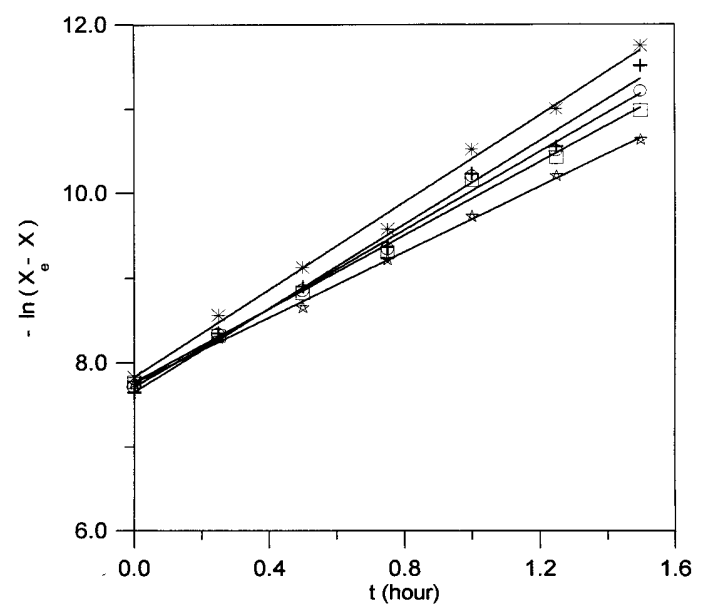

Fig. 3. Plot of $\ln \left(X_{\mathrm{e}}-X\right)$ vs $t$ of $o$-nitrophenol at $25^{\circ} \mathrm{C} ;(*)$ $1.0 \times 10^{-4} \mathrm{M},(+) 1.67 \times 10^{-4} \mathrm{M},\left(\right.$ o) $2.5 \times 10^{-4} \mathrm{M}(\square)$ $4.0 \times 10^{-4} \mathrm{M}$, (约) $5.0 \times 10^{-4} \mathrm{M}$.

time; $t$ : time; $k$ : rate constant; and $I$ is the integration constant.

The rate of adsorption decreases as $X$ approaches its equilibrium value $X_{\mathrm{e}}$. The plot of $\ln \left(X_{\mathrm{e}},-X\right)$ vs $t$ gives straight lines and was obtained for various initial concentrations of $o-, m$ and $p-\mathrm{Nph}$ at constant temperature. The rate of adsorption of $o-, m$ - and $p-\mathrm{Nph}$ decreases with time at constant temperature, as shown in Figs. $2-4$. The values of $k$ given in Table 1 , show that at constant concentration the rate of adsorption increases sharply on increasing the temperature, for all three nitrophenols.

The activation energies were calculated from the linearized Arrhenius equation:

$\ln k=\ln A-\frac{E_{a}}{R T}$

$k$ : rate constant; $E_{\mathrm{a}}$ : activation energy; $R$ : gas constant; $T$ : temperature $A$ : preexponential factor.

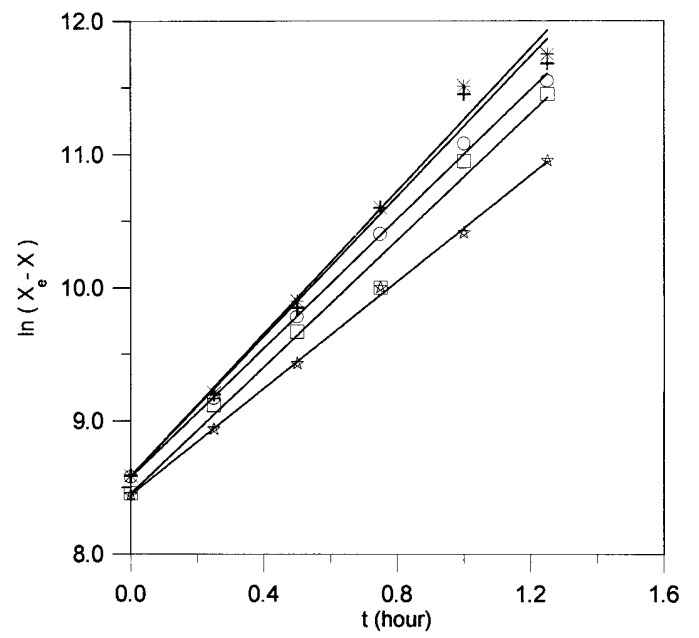

Fig. 4. Plot of $\ln \left(X_{\mathrm{e}}-X\right)$ vs $t$ of $m$-nitrophenol at $25^{\circ} \mathrm{C} ;(*)$ $1.0 \times 10^{-4} \mathrm{M},(+) 1.67 \times 10^{-4} \mathrm{M},\left(\right.$ o) $2.5 \times 10^{-4} \mathrm{M}(\square)$ $4.0 \times 10^{-4} \mathrm{M}$, (氾) $5.0 \times 10^{-4} \mathrm{M}$.

Table 1

Kinetic parameters of nitrophenols at zeolite-water interface ${ }^{\mathrm{a}}$

\begin{tabular}{lll}
\hline $\begin{array}{l}\text { Nitrophenols at concentration } \\
5.0 \times 10^{-4} \mathrm{Mol} / \mathrm{l}\end{array}$ & $T / K$ & $10^{4} \mathrm{k} / \mathrm{s}^{-1}$ \\
\hline \multirow{2}{*}{ Para } & & \\
& 298 & 4.7 \\
\multirow{3}{*}{ Ortho } & 313 & 6.6 \\
& 323 & 8.2 \\
& 298 & 5.4 \\
Meta & 313 & 5.9 \\
& 323 & 6.3 \\
& 298 & 5.6 \\
& 313 & 6.0 \\
& 323 & 6.4
\end{tabular}

a The standard error of the $k$ values was calculated to be in the range of $\pm 0.06-0.07$. 


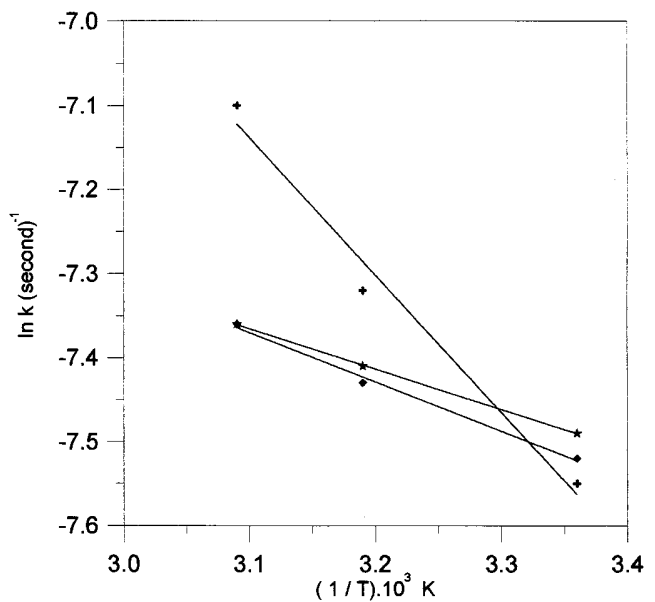

Fig. 5. Plot of $\ln k$ vs $\mathrm{I} / T$ for the adsorption of $p$-nitrophenol $(+), o$-nitrophenol $(\bullet)$ and $m$-nitrophenol $(\star)$.

For all the three nitrophenols, a plot of $\ln k$ against the reciprocal of absolute temperature, $1 / T$, give straight lines as shown in Fig. 5 and the corresponding $E_{\mathrm{a}}$, were determined from the slope of each linear plot as shown in Table 2. As known when the rate is controlled by film diffusion mechanism, the activation energy is very small (less than $20 \mathrm{~kJ} / \mathrm{mol}$ ) [7]. Fig. 6 shows the plot of $\ln (k / T)$ against the reciprocal of absolute temperature, $1 / T$, for the three nitrophenols, following the Eyring equation [7].,

$\ln \left(\frac{k}{T}\right)=\ln \left(\frac{\mathrm{k}}{\mathrm{h}}\right)+\frac{\Delta S^{*}}{R}-\frac{\Delta H^{*}}{\mathrm{R} T}$

where $\mathrm{k}$ and $\mathrm{h}$ are Boltzmann's and Plank's constants, respectively. The entropy of activation $\Delta S^{*}$ and enthalpy of activation $\Delta H^{*}$ for this step have been evaluated from the intercept and the slope of each linear plot. The free energies of

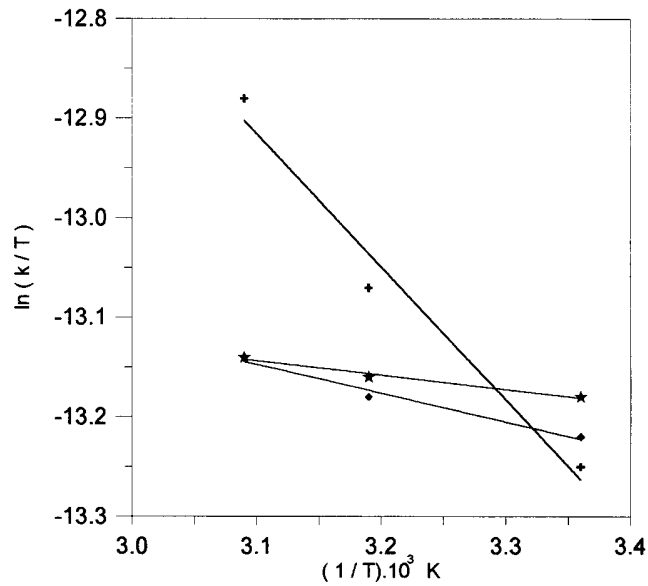

Fig. 6. Plot of $\ln k / \mathrm{T}$ against $1 / T p$-nitrophenol $(+)$, $o$-nitrophenol $(\bullet)$ and $m$-nitrophenol $(\star)$.

activation $\Delta G^{*}$ equal to $\Delta H^{*}-T \Delta S^{*}$ have also been computed at $298 \mathrm{~K}$ and given in Table 2 .

The corresponding values of enthalpy of activation $\Delta H^{*}$, entropy of activation $\Delta S^{*}$, and free energy of activation $\Delta G^{*}$ have been evaluated using Eyring's Eq. (2) of absolute reaction rate. The activation energy and enthalphy of activation increased with shift of substition position from $m$ to $o$ - and from $o$ - to $p$-. This must be due to increased intermolecular hyrogen bonding resulting in association among the molecules, espicially in case of $\mathrm{p}-\mathrm{Nph}$.

So it may be said that the molecule of $\mathrm{p}-\mathrm{Nph}$ grows up and the surface of the molecule increases [9]. But the small values of $E_{\mathrm{a}}$ and $\Delta H^{*}$ for $o$ - and $m$ - nitrophenols, indicates that intramolecular hydrogen bonding occurs and the surface of the molecule is smaller. Thus, it can be stated that $o$ - and $m$-nitrophenols are adsorbed at less amounts on the surfaces of zeolite than p-

Table 2

Calculated thermodynamic values for dynamic adsorption of nitrophenols at zeolite-water interface ${ }^{\mathrm{a}}$

\begin{tabular}{lcccc}
\hline Substances & $E_{\mathrm{a} / \mathrm{kJ} \mathrm{mol}} \mathrm{kJ}^{-1}$ & $\Delta H^{*} / \mathrm{kJ} \mathrm{mol}^{-1}$ & $\Delta S^{*} / \mathrm{J} \mathrm{mol}^{-1} \mathrm{~K}^{-1}$ & $\Delta G^{*} / \mathrm{kJ} \mathrm{mol}^{-1}$ \\
\hline$p$-nitrophenol & 14 & 11 & -320 & 110 \\
$o$-nitrophenol & 4.9 & 2.4 & -340 & 110 \\
$m$-nitrophenol & 3.9 & 1.2 & -350 & 110
\end{tabular}

\footnotetext{
a The $\Delta H_{\mathrm{p}-\mathrm{Nph}}^{*}$ values are accurate to $\pm 1 \mathrm{~kJ} \mathrm{~mol}^{-1}$, the $\Delta H_{\mathrm{o}-\mathrm{Nph}}^{*}$ values to $\pm 0.2 \mathrm{~mol}^{-1} . \Delta H_{\mathrm{p}-\mathrm{Nph}}^{*}$ values to $\pm 0.1 \mathrm{~kJ} \mathrm{~mol}^{-1}$. For o-m-pNph, all the $\Delta S^{*}$ values are accurate to $\pm 3 \mathrm{~J} \mathrm{~mol}^{-1} \mathrm{~K}^{-1}$, all the $\Delta G^{*}$ values to $\pm 14 \mathrm{~kJ} \mathrm{~mol}^{-1}$.
} 
Nph. As expected, the entropy of activation $\Delta S^{*}$ for all nitrophenols are smaller than zero. As shown in Table 2 entropy of activation $\Delta S^{*}$ and free energy of activation $\Delta G^{*}$ were determined to be about the same for the adsorption of all the nitrophenols. Also, it is noted with considerable interest that $\Delta H^{*}$ obtained from the Eyring equa-

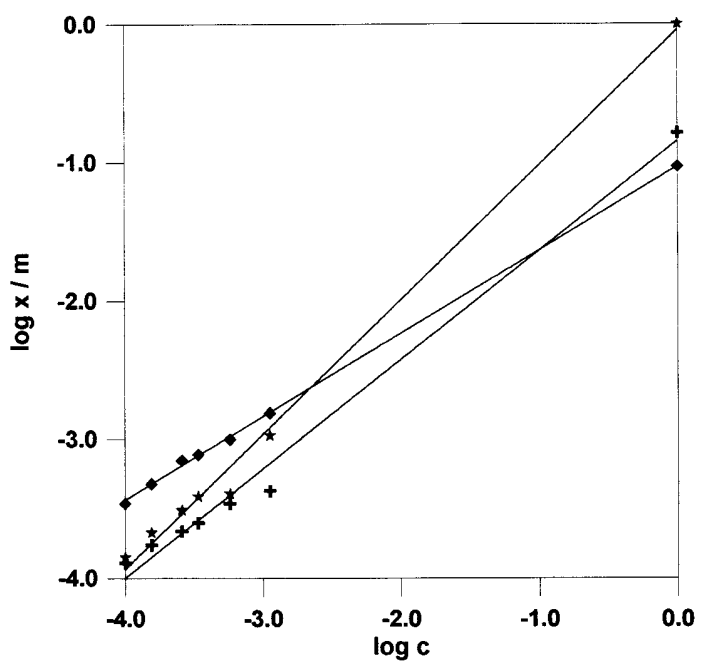

Fig. 7. Application of Freundlich equation to adsorption of $p$-nitrophenol $(+), o$-nitrophenol $(\bullet)$ and $m$-nitrophenol $(\star)$ on clinoptilolite at $25^{\circ} \mathrm{C}$.

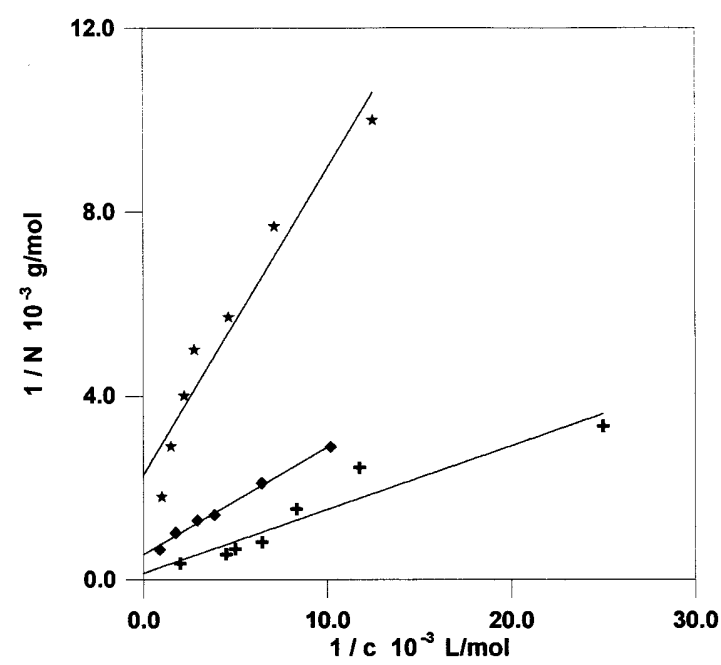

Fig. 8. Application of Langmuir equation to adsorption of $p$-nitrophenol $(+), o$-nitrophenol $(\diamond)$ and $m$-nitrophenol $(\star)$ on clinoptilolite at $25^{\circ} \mathrm{C}$. tion is lower than $T \Delta S^{*}$, showing that the reorientation step is mostly entropy controlled at the activated state [7].

\subsection{Adsorption isotherms}

The adsorption model suitable for the concentration range of $1.0 \times 10^{-4}-5.0 \times 10^{-4} \mathrm{Mol} / 1$ was fitted to Freundlich isotherm as in shown Fig. 7.

$\log \left(\frac{x}{m}\right)=\log k+n \log c$

where, $x$ is the amount of solute per unit weight of adsorbent $(\mathrm{Mol} / \mathrm{g}), c$ is the equilibrium concentration $(\mathrm{Mol} / \mathrm{l})$ and $k$ and $n$ are empirical constants which are determined from the intercept and slope of the isotherm. Another adsorption isotherm used in this study is the Langmuir equation [5]. In linearized form this isotherm is as follows,

$\frac{1}{N}=\frac{1}{N_{\max }}+\left(\frac{k_{2}}{k N_{\max }}\right) \frac{1}{c}$

where, $N$ is the number of adsorbed molecules per unit area $(\mathrm{Mol} / \mathrm{g}), c$ is the equilibrium concentration $(\mathrm{Mol} / \mathrm{l})$ and $N_{\max }$ is the total number of adsorption sites per unit area $\left(g_{\mathrm{Nph}} / g_{\text {zeolite }}\right)$. The plot of $1 / N$ vs $1 / c$ give the straight lines shown in Fig. 8. The $N_{\max }$ and $k_{2} / k_{1}$ for this step have been evaluated from the intercept and the slope of each linear plot. Rough estimates of $N_{\max }$ of the zeolite surface by $o-, m$ - and $p-\mathrm{Nph}$ are $0.26,0.06,1.02$ $\left(g_{\mathrm{Nph}} / g_{\text {zeolite }}\right)$, respectively. Thus, $o-, m-\mathrm{Nph}$ are less adsorbed, compared to the $p-\mathrm{Nph}$. As seen in Fig. 9, the adsorption isotherm of $o-, m-$, and $p$-Nph on clinoptilolite were L-shaped $[6,8]$. The adsorption isotherm of $o-$, and $m-\mathrm{Nph}$ is a onestep curve (L). This one-step curve in Fig. 9 shows that, as more sites on the surface of the adsorbent are filled by water molecules because of intramolecule structures of $o$ - and $m$-nitrophenols. It will be rather difficult to have adsorbed by finding a vacant site on the surface by solute molecules and this behaviour is consistent with the formation of a monomolecular layer of solute on adsorbent surface. This implies that the adsorbed solute molecule is not vertically oriented 


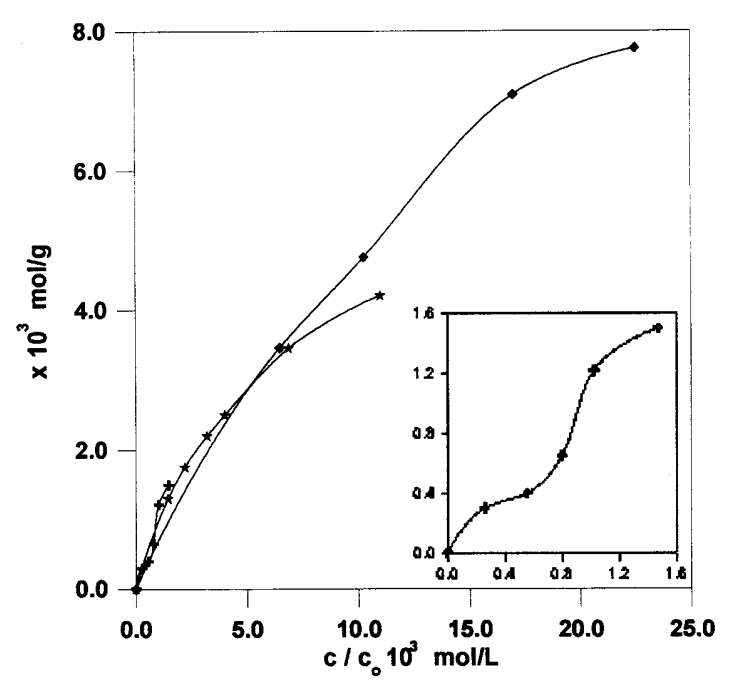

Fig. 9. Adsorption isotherms of $p$-nitrophenol $(+), o$-nitrophenol $(\diamond)$ and $m$-nitrophenol $(\star)$ on clinoptilolite at $25^{\circ} \mathrm{C}$.

or that there is no strong competition from the solvent $[6,8]$. However, the adsorption isotherm of $\mathrm{p}-\mathrm{Nph}$ is a two-step curve (L) because of strong intermolecular forces. The first and second curvature in Fig. 9 (enlarged curve on the right hand side) shows the step wise increase of the adsorbed amounts of $p-\mathrm{Nph}$ of about $c / c_{0}=0.4$ and 1.2 , respectively. The former behaviour is compatible with the formation of a monomolecular layer of solute on adsorbent surface. The latter behaviour was attributed by Giles et al $[6,8]$ to the adsorption on: (a) the first layer; (b) a new region of the substrate; or (c) a part of the orginal surface. The shape of isotherms reveals that the adsorption at the second curvature is influenced by an activated diffusion process and there is little probability that the process takes place on fresh surface. Also, the adsorbed amount at $c / c_{0}$ values lower than approx. 0.4 and 1.2, does not appear to be sufficiently important, so that the mere rearrangement of the adsorbed state alone causes such a significant increase in the adsorption. In brief, if the orientation were at first flat and later end-on, the adsorption of $\mathrm{p}$-Nph would follow the monolayer and then multilayer mechanism.

\section{References}

[1] F. Caturla, M.J.M. Martin, S. Molina, R.F. Rodrigez, F. Torregrosa, J. Colloid Interface Sci. 124 (1988) 528-534.

[2] A. Wolborska, Water Research 23 (1989) 85-91.

[3] F. Esenli, L Özpeker, Zeolitic diagenesis of Neogene basin and the mineralogy of heulandites-clinoptilolites in Gördes around, Bulletin of the Geological Congress of Turkey, 1993, pp. 1-18.

[4] F., Esenli, Quantitative analysis of heulandites-clinoptilolites in zeolite containing tuffs from Gördes region by X-ray diffraction, Publication of the Chamber of Geological Engineers of Turkey, (1993) pp.42-49.

[5] J. Mortensson, N. Arwin, L Lundström, T.H. Ericson, J. Colloid Interface Sci. 155 (1993) 30-36.

[6] C. Giles; T. MacEwan; S. Nakwa; D. Smith, J. Chem. Soc., 3973, (1960).

[7] G. Atun, T. Sismanoglu, J. of Environmental Sci. and Health A31 (8) (1996) 2055-2069.

[8] J.W. Galbraith, C.H. Giles, A.G. Halliday, A.S.A. Hassan, D. Mcallister, C. Macaulay, N.W. Machmillan, J. Appl. Chem. 8 (1958) 416-423.

[9] T.W. Graham Solomans, Organic Chemistry, 5th edn, John Wiley \& Sons Inc., Florida, 1992. 